Egyptian

Orthodontic Journal

\title{
DIAGNOSTIC CAPABILITY OF LITTLE IRREGULARITY INDEX TO ESTIMATE ARCH LENGTH DISCREPANCY
}

\author{
Medhat EISakhawyh ${ }^{1}$ Safaa M Gaballa ${ }^{2}$ \\ Safaa A Ghobashy ${ }^{3}$ Rania A Hanafy ${ }^{4}$
}

\section{ABSTRACT:}

Objective: The aim of the present study is to evaluate the diagnostic capability of Little irregularity index (LII) to estimate arch length deficiency (ALD) in a dental arch.

Material and methods: Five hundred dental casts were selected from 1000 study models from the patients (12-14 years old) attending the Dental Clinic of Orthodontic, in Tanta University. The casts were categorized according to sex, degree of crowding and upper or lower. In order to classify cases according to degree of crowding ALD was calculated as the difference between available and required space in each dental arch anterior to the first permanent molars. LII was calculated on each cast by measuring the linear displacement between the six anterior teeth, and was contrasted with the dichotomized ALD. The receiver operator characteristic curve (ROC) was applied to suggest optimal cut-off points for LII to estimate ALD.

Results: High correlation was observed between ALD and LII (-0.91, $P<0.0001)$. According to ROC curve, LII of $>0,>3.5,>6 \mathrm{~mm}$ were optimized cut-off points to estimate minimum, moderate and severe crowding respectively. Regarding the analysis of ROC

\footnotetext{
${ }^{1}$ Professor of orthodontics, Faculty of Dentistry Tanta University

${ }^{2}$ Professor of orthodontics, Faculty of Dentistry Tanta University

${ }^{3}$ Associate professor of orthodontics, Faculty of Dentistry Tanta University

${ }^{4}$ Student for master degree in orthodontics.
} 
Egyptian

Orthodontic Journal

curve for minimum crowding cases, LII was found to have the highest diagnostic capability of $>0 \mathrm{~mm}$ or minimum crowding with sensitivity 1.00 and specificity 1.00, then the moderate crowding with sensitivity 96.45 and specificity 97.96 and severe crowding with of sensitivity 91.95 and specificity 84.05 .

Conclusion: The results of ROC provided useful insights of the potentiality of $L I I$ to estimate negative ALD of the dental arch.

\section{INTRODUCTION}

Crowding is the main reason why people request orthodontic treatment ${ }^{(1-3)}$. Dental crowding is defined as a discrepancy between tooth size and jaw size that results in misalignment of tooth row and malocclusion $^{(4)}$.

Over the past hundred years, several methods and indices have been reported in the literature for the assessment of malocclusion in quantitative manner ${ }^{(4-7)}$. In addition, the index of orthodontic treatment need $^{(8)}$, and the Index of Complexity, Outcome, and need ${ }^{(9)}$.

An index is defined as a numerical value describing the relative status of population on a graduated scale with definite upper and lower limits which is designed to permit and facilitate the comparison with other population ${ }^{(10)}$.Certain characteristics of an ideal index of malocclusion were identified and include: reliability or reproducibility, validity, simplicity, objectivity, inexpensive procedure, equipment, ease of performance and achievement of rapid results ${ }^{(11)}$. Several indices have been reported for assessing malocclusion for epidemiological studies ${ }^{(12)}$ .Only LII ${ }^{(12-14)}$ combines the advantage of being less time consuming and has been previously been used in epidemiological surveys. It measures the degree of labio-lingual displacement of any slipped contact points of the six anterior teeth. The method described by Little ${ }^{(13)}$ recognizes the problem that contact points and incisal edges that the brass wire is used to measure are areas of approximation rather than discrete contact points, he offered measuring the sum of the labio-lingual overlap of six anterior. 
Egyptian

Orthodontic Journal

ALD refers to an imbalance between the available and required spaces in dental arch to accommodate all teeth aligned perfectly ${ }^{(15,16)}$. When available space results in a deficiency, a negative ALD or dental crowding is diagnosed. When the available space required for adequate tooth alignment, a positive ALD or dental spacing is diagnosed. The ALD can be carried out by several methods and the results may be expressed directly in millimeter or by means of crowding index, all of these were proposed to be used in clinical setting or in dental cast ${ }^{(4,17,18)}$.

The correlation between LII and anterior ALD measured from canine to canine for the lower teeth has been previously reported by Harris et $\mathrm{al}^{(18)}$. The association between incisor irregularity and ALD, when measured on complete dental arches and not only from canine to canine has not been reported until Bernabe and Flores ${ }^{(19)}$ contrasted complete ALD and the irregularity index and applied it to upper and lower arches.

The present study was conducted to evaluate the diagnostic capability of LII to measure crowding in whole dental arch in epidemiological survey compared with the conventional ALD by using ROC to suggest optimal cut off points for LII which allowed for estimation of ALD.

\section{MATERIAL AND MATHODS}

A sample of 1000 upper and lower study models was randomly selected from a population that attends the Dental Clinic of Orthodontic in Tanta University according to the following:

1- Children ranged between 12 and 16 years.

2- permanent teeth was fully erupted and present from right $1^{\text {st }}$ permanent molar to the left $1^{\text {st }}$ permanent molar.

3- No history of previous orthodontic treatment, no obvious interproximal or occlusal wear of teeth and no extraction.

Models were eliminated from sample because the presence of:

1- Broken study models.

2- Gross restorations, build ups, crowns, onlays, class II amalgam or proximal restoration that affects the mesiodistal diameter. 
3- Congenitally missing teeth and impacted teeth.

4- Gross carious teeth with involvement of the mesial and distal surfaces.

5- Supernumerary teeth.

After the selection process was completed the final sample consisted of 500 upper and lower models.

\section{Calculation of ALD ${ }^{(20) .}$}

1- The sum of the greater mesiodistal width of each tooth was measured from the right $2^{\text {nd }}$ premolar to the left $2^{\text {nd }}$ premolar. Measurement of the mesiodistal diameter of the teeth was made directly on the casts by using manual Boley gauge ( Dentarum, Pforzheim, Germany ) accurate to the nearest $0.1 \mathrm{~mm}$ with fine tips to improve access to interproximal distance. The Boley gauge tip was held perpendicular to the long axis of each tooth and the mesiodistal dimensions were obtained by measuring the maximum distance between the two sides of tooth on a line parallel to the occlusal and perpendicular to buccal surfaces.

2- The amount of space available is determined by adapting a length of 0.025 inch diameter brass wire to fit from the mesial marginal ridge of the left first permanent molar around the arch to the mesial marginal ridge of the right first permanent molar.

- The brass wire should pass over the imagined correct position of the cuspid, the center of the buccal cusps of the bicuspids and the incisal edge of the lower teeth while in the maxilla passes along the central fossae of the posterior teeth and cingula of anterior teeth.

- The wire should be a smooth arch, free from kinks and should simulate the desired arch form.

3- The length of the brass wire, determined in millimeter, is regarded as the available space for the total complement of the dentition which consisted of: the 1st and 2nd bicuspids, cuspids and lateral and central incisors of both the right and left sides of the arch.

To calculate ALD, the space available was subtracted from the space required. Then the results were interpreted as follow ${ }^{(21)}$ : 
- Dental arches with negative ALD were defined as crowding.

- Dental arches with positive ALD were defined as spacing.

- Dental aches with negative ALD from0 to $3 \mathrm{~mm}$ were defined as minimum crowding.

- Dental arches with negative ALD from 3 to $6 \mathrm{~mm}$ were defined as moderate crowding.

- Dental arches with negative ALD more than $6 \mathrm{~mm}$ were defined as severe crowding.

\section{Calculation of Little irregularity index ${ }^{(13)}$ ( Fig 1):}

- Measurement of the horizontal linear displacement of anatomic contact points of six maxillary and mandibular anterior teeth was obtained directly from the study models, using electronic digital caliper (Stainless hardened Sakara).

- The cast was viewed from above, sighting down onto the incisal edges of the anterior teeth, and the caliper was held consistently parallel to the occlusal plane while obtaining each measurement.

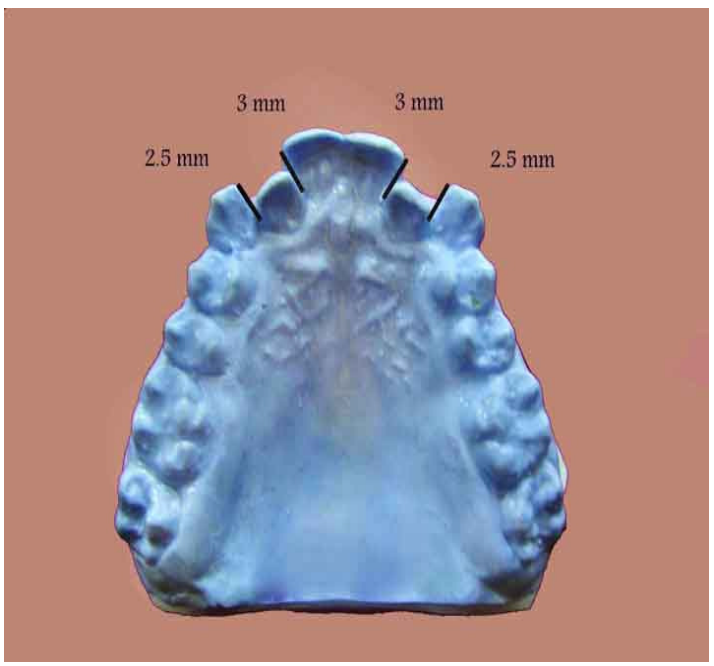

Fig (1) Horizontal linear displacement of contact points 
Egyptian

Orthodontic Journal

\section{Assessment of reproducibility:}

Intra-examiner reproducibility of the method of measurement was tested. Measurements were undertaken twice, when the first and second measurements differed by more than $0.2 \mathrm{~mm}$, the tooth was measured again and this third measurement was then registered. When both measurements differed by less than $0.2 \mathrm{~mm}$, the original measurement was accepted.

\section{Statistical analysis:}

The data were judged statistically and analyzed as follow ${ }^{(22)}$ :

1- Descriptive statistics were calculated as frequencies and percents for qualitative variables (sex, jaw, crowding categories) while means and standard deviations for quantitative variables (ALD and LII).

2- Comparison of crowding condition between males and females as well as between upper and lower arches was done using Mann Whitney U test.

3- Comparison of ALD and LII among the crowding groups was done using analysis of variance and Kruskal Wallis test followed by Scheff post hoc test and Mann Whitney $U$ test respectively for pairwise comparison.

4- Comparison of ALD between sexes and arches was done using $t$ test while the same comparison for LII was done using Mann Whitney U test.

5- Non parametric correlation between ALD and LII was done using Spearman rho.

\section{Receiver Operator Characteristic Curve:}

ROC describes the inherent detection characteristic of the diagnostic test. It was used to assess the accuracy of LII to detect crowding using cut-off points based on ALD. The ROC provides a quantitative assessment of diagnostic capability of LII to estimate ALD. The better method appears close to the upper left hand corner of ROC graph. ROC plots the true positive (TP) ratio (sensitivity) versus false positive (FP) ratio (specificity) while the cut-off value for a positive or negative result is varied (fig 2). 


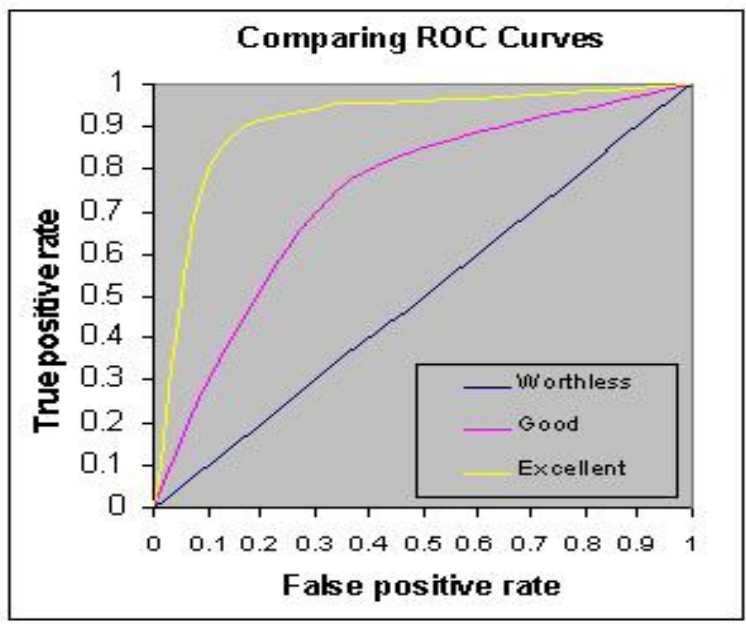

Fig (2) ROC curve

The area under curve, sensitivity, specificity ${ }^{(23)}$ with confidence intervals for both measures was calculated and suitable cut off points were selected.

- Sensitivity: is the true positive (TP) ratio and is calculated as (TP/ TP+False negative). This measures the proportion of patient with specific condition (identify ALD when it is really present).

- Specificity: is the true negative (TN) ratio and is calculated as (TN/ TN+False Positive). This measures the proportion of patient without specific condition.

\section{RESULTS}

The results of the present study will be presented in Tables (1:13).

Table (1) Sample description.

\begin{tabular}{|c|c|c|}
\hline \multirow{2}{*}{ Sex } & Male & $\mathrm{N}=263(52.6 \%)$ \\
\cline { 2 - 3 } & Female & $\mathrm{N}=237(47.4 \%)$ \\
\hline \multirow{2}{*}{ Jaw } & Upper & $\mathrm{N}=274(54.8 \%)$ \\
\cline { 2 - 3 } & Lower & $\mathrm{N}=226(45.2 \%)$ \\
\hline
\end{tabular}


Table (2) Distribution of ALD and its categories among study sample.

\begin{tabular}{|c|c|c|}
\hline \multirow{4}{*}{ ALD } & Min- max & $-13.00-16.00$ \\
\cline { 2 - 3 } & Mean \pm SD & $-4.18 \pm 4.52$ \\
\hline \multirow{4}{*}{ Spacing/ crowding } & Spacing: & $\mathrm{N}=98(19.6 \%)$ \\
\cline { 2 - 3 } & Normal: & $\mathrm{N}=90(18 \%)$ \\
\cline { 2 - 3 } & Mild crowding: & $\mathrm{N}=96(19.2 \%)$ \\
\cline { 2 - 3 } & Moderate crowding: & $\mathrm{N}=110(22 \%)$ \\
\cline { 2 - 3 } & Severe crowding: & $\mathrm{N}=106(21.2 \%)$ \\
\hline Total & & $500(100 \%)$ \\
\hline
\end{tabular}

Table (3) Distribution of crowding in different sexes.

\begin{tabular}{|l|c|c|}
\hline \multicolumn{1}{|c|}{ Spacing/ crowding } & $\begin{array}{c}\text { Male } \\
\text { N (\%) }\end{array}$ & $\begin{array}{c}\text { Female } \\
\text { N (\%) }\end{array}$ \\
\hline Spacing & $40(17.4)$ & $58(21.4)$ \\
\hline Normal & $34(14.8)$ & $56(20.6)$ \\
\hline Minimum crowding & $43(18.8)$ & $53(19.5)$ \\
\hline Moderate crowding & $62(27)$ & $48(17.7)$ \\
\hline Severe crowding & $50(21.8)$ & $56(20.6)$ \\
\hline \multicolumn{1}{|c|}{ Total } & $229(100)$ & $271(100)$ \\
\hline $\begin{array}{l}\text { Z of MWU test } \\
\text { P value }\end{array}$ & \multicolumn{2}{|c}{0.52} \\
\hline
\end{tabular}

Table (4) Distribution of crowding in different arches.

\begin{tabular}{|l|c|c|}
\hline \multicolumn{1}{|c|}{ Spacing/ crowding } & $\begin{array}{c}\text { Upper arch } \\
\text { N (\%) }\end{array}$ & $\begin{array}{c}\text { Lower arch } \\
\text { N (\%) }\end{array}$ \\
\hline Spacing & $60(22,9)$ & $38(15.9)$ \\
\hline Normal & $47(17.9)$ & $43(18)$ \\
\hline Minimum crowding & $45(17.1)$ & $51(21.4)$ \\
\hline Moderate crowding & $58(22.1)$ & $52(21.8)$ \\
\hline Severe crowding & $52(19.8)$ & $54(22.7)$ \\
\hline \multicolumn{1}{|c|}{ Total } & $262(100)$ & $238(100)$ \\
\hline Z of MWU test & \multicolumn{2}{|c}{1.10} \\
P value & \multicolumn{2}{|c|}{0.27} \\
\hline
\end{tabular}


Egyptian

Orthodontic Journal

Table ( 5) comparison of ALD between males and females.

\begin{tabular}{|l|c|c|}
\hline & Males & Females \\
\hline Mean \pm SD & $5.07 \pm 3.95$ & $4.93 \pm 3.87$ \\
\hline MWU test & & 0.29 \\
P value & & 0.77 \\
\hline
\end{tabular}

Table ( 6) Comparison of ALD between upper and lower arches.

\begin{tabular}{|l|c|c|}
\hline & Upper & Lower \\
\hline Mean \pm SD & $-4.27 \pm 4.70$ & $-4.08 \pm 4.35$ \\
\hline T test & & 0.39 \\
P value & & 0.70 \\
\hline
\end{tabular}

Table ( 7) Comparison of LII between males and females.

\begin{tabular}{|l|c|c|}
\hline & Males & Females \\
\hline Mean \pm SD & $5.07 \pm 3.95$ & $4.93 \pm 3.87$ \\
\hline MWU test & & 0.29 \\
P value & & 0.77 \\
\hline
\end{tabular}

Table (8) Comparison of LII between upper and lower arches.

\begin{tabular}{|l|c|c|}
\hline & Upper & Lower \\
\hline Mean \pm SD & $5.47 \pm 4.01$ & $4.52 \pm 3.75$ \\
\hline MWU test & \multicolumn{2}{|c|}{2.26} \\
P value & \multicolumn{2}{|c|}{0.76} \\
\hline
\end{tabular}

Table (9) Comparison of ALD among different spacing/ crowding groups.

\begin{tabular}{|l|c|c|c|c|c|}
\hline & Spacing & Normal & Mild crowding & Moderate crowding & Severe crowding \\
\hline Min, max & $2.0,13.0$ & 0,0 & $-3.0,-0.5$ & $-6.0,-3.5$ & $-16.0,-6.5$ \\
\hline Mean \pm SD & $6.71 \pm 3.80^{\mathrm{a}}$ & $0 \pm 0^{\mathrm{b}}$ & $-2.21 \pm 0.78^{\mathrm{c}}$ & $-5.10 \pm 0.86^{\mathrm{d}}$ & $-9.41 \pm 2.41^{\mathrm{e}}$ \\
\hline ANOVA & \multicolumn{5}{|c|}{536.84} \\
P value & \multicolumn{5}{|c|}{$<0.0001^{*}$} \\
\hline
\end{tabular}

* Statistically significant at $\mathrm{P} \leq 0.05$ 
Table (10) Comparison of LII among different spacing/ crowding groups.

\begin{tabular}{|l|c|c|c|c|c|}
\hline & Spacing & Normal & Mild crowding & Moderate crowding & Severe crowding \\
\hline Min, max & 0,8 & 0,0 & $0.5,5.0$ & $2.5,15.0$ & $0.5,17.0$ \\
\hline Mean \pm SD & $0 \pm 0^{\mathrm{a}}$ & $0 \pm 0^{\mathrm{a}}$ & $2.15 \pm 0.82^{\mathrm{b}}$ & $6.19 \pm 2.12^{\mathrm{c}}$ & $9.57 \pm 2.77^{\mathrm{d}}$ \\
\hline $\begin{array}{l}\text { X2 of Kruskal } \\
\text { Wallis test } \\
\text { P value }\end{array}$ & \multicolumn{5}{|c|}{288.53} \\
\hline
\end{tabular}

* Statistically significant at $\mathrm{P} \leq 0.05$

a,b, c, d and e: Different letters denote statistically significant differences between pairs of groups, value within spacing column followed by the same letter in no crowding column were not statistically significant.

\section{Correlation between ALD and LII:}

Figure (3) shows the scatter plot between ALD and LII. Spearman rho-0.91, $\mathrm{P}<0.0001$, showing strong, negative and statistically significant non parametric correlation.

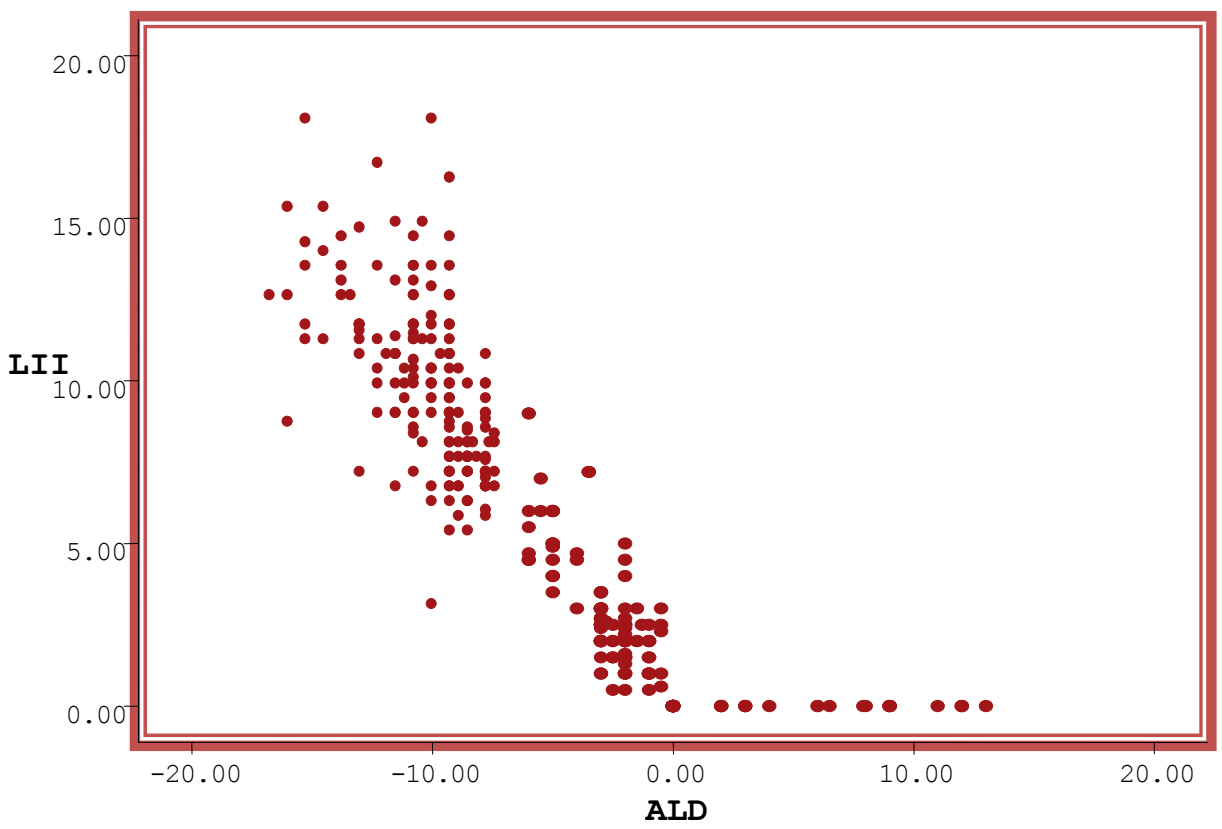

Fig (3): Correlation between ALD and LII 


\section{Regarding the ROC analysis:}

LII was compared to negative ALD greater than $0 \mathrm{~mm}$ (minimally crowded arch. The area under the curve was $100 \%$. An optimized cut off point $>0$ on LII was chosen to estimate negative ALD. The cut off point had sensitivity of $100.00(95 \%$ CI $96.2-100.0)$ and specificity 100.00 (95\% 93.0 - 100.0) (Table 11 and Figure 4).

Table (11): ROC for ability of LII to detect minimum crowded arches

\begin{tabular}{|lc|}
\hline N minimum crowding cases & 96 \\
\hline N non minimum crowding & 188 \\
\hline Area under curve AUC (SE) & $1.00(0)$ \\
\hline Confidence interval (lower, upper) & $0.98,1.00$ \\
\hline P value & $<0.0001^{*}$ \\
\hline Cut off point & $>0$ \\
\hline Sensitivity (CI) & $100(96.2-100)$ \\
\hline Specificity (CI) & $100(93-100)$ \\
\hline
\end{tabular}

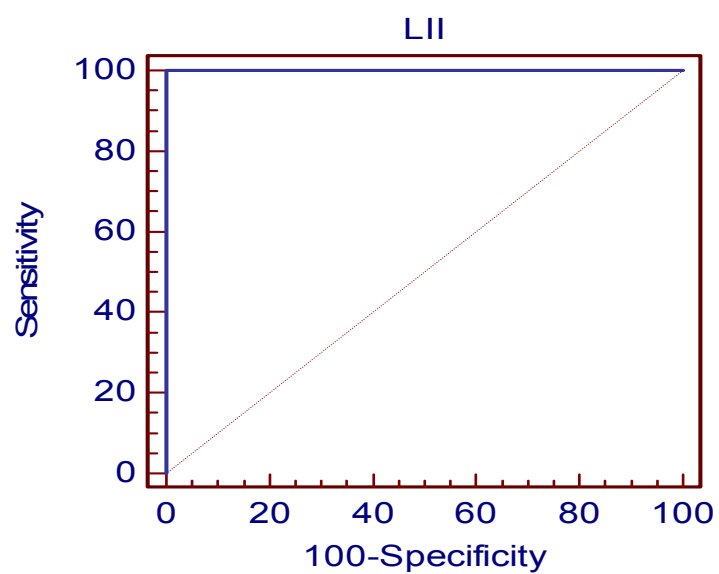

Fig (4) ROC curve plotting LII contrasted with minimum crowded arch. 
Similarly when LII was contrasted with negative ALD greater than $3 \mathrm{~mm}$ (moderately crowded arches), an optimized cut off point $>3.5$ on LII was chosen, it presented a sensitivity of $96.45(95 \% 92.8-98.6)$ and specificity $97.96(95 \% 94.2-99.6)$. In this case the area below the ROC was 0.99(Table 12 and Figure 5).

Table (12) ROC for ability of LII to detect moderately crowded arches

\begin{tabular}{|lc|}
\hline N moderately crowded cases & 216 \\
\hline N non moderately crowded cases & 284 \\
\hline Area under curve AUC (SE) & $0.99(0.004)$ \\
\hline Confidence interval (lower, upper) & $0.98,0.99$ \\
\hline Z statistic & 131.18 \\
\hline P value & $<0.0001^{*}$ \\
\hline Cut off point & $>3.5$ \\
\hline Sensitivity (CI) & $96.45(92.8-98.6)$ \\
\hline Specificity (CI) & $97.96(94.2-99.6)$ \\
\hline
\end{tabular}

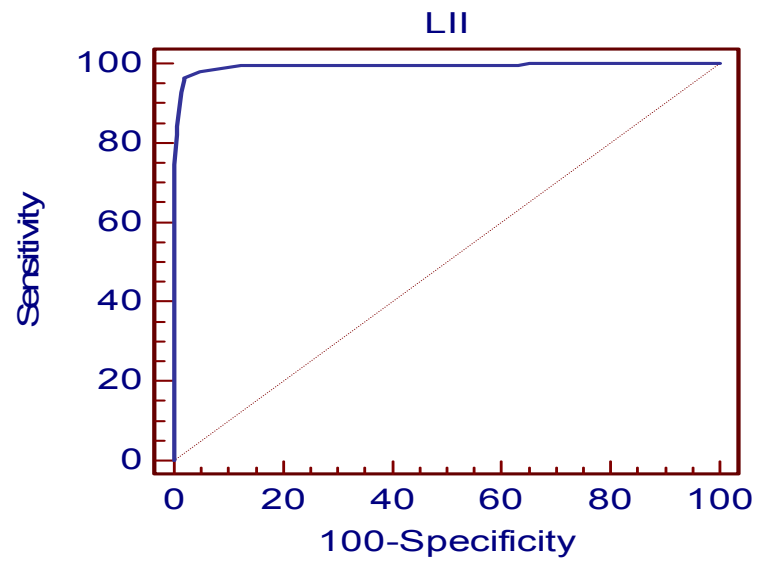

Fig (5) LII contrasted with moderate crowded arch 
Finally when LII contrasted with severely crowded arches an optimized cut off point of $>6$ on LII was chosen, it had a sensitivity of 91.95(84.1- 96.7) and specificity of $84.05(79.0-88.3)$.The area under ROC was 0.93(0.02) (Table1 and Figure 6).

Table (13) ROC for ability of LII to detect severely crowded arches

\begin{tabular}{|lc|}
\hline N severely crowded cases & 106 \\
\hline N non severely crowded cases & 394 \\
\hline Area under curve AUC (SE) & $0.93(0.02)$ \\
\hline Confidence interval (lower, upper) & $0.90,0.96$ \\
\hline Z statistic & 28.48 \\
\hline P value & $<0.0001^{*}$ \\
\hline Cut off point & $>6$ \\
\hline Sensitivity (CI) & $91.95(84.1-96.7)$ \\
\hline Specificity (CI) & $84.05(79.0-88.3)$ \\
\hline
\end{tabular}

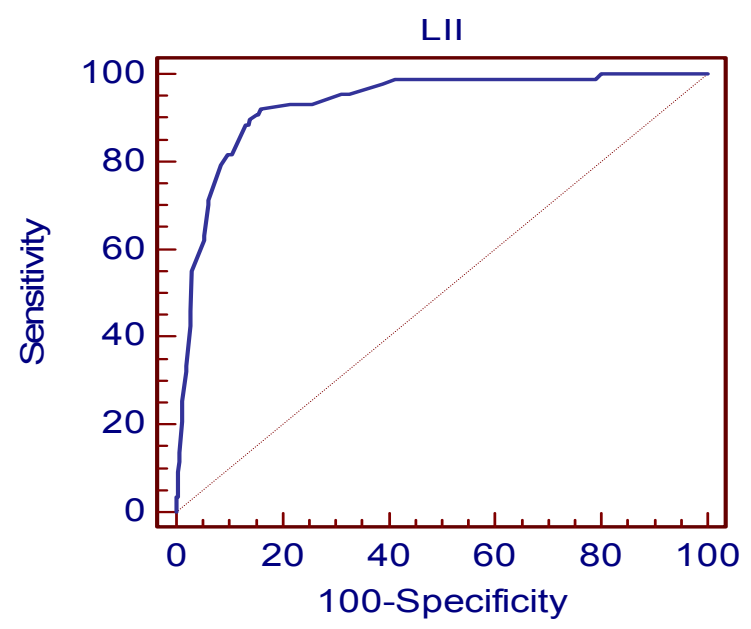

Fig (6) LII contrasted with severe crowded arch 
Egyptian

Orthodontic Journal

\section{DISCUSSION}

The current study examined two methods used for space analysis, and tested the validity of simple diagnostic test that relies on measuring incisor irregularity to detect the crowding in whole dental arch. Thus far, the best method for determining the validity of diagnostic measure is the ROC which is equivalent to plotting sensitivity and specificity of LII at all its possible cut off points ${ }^{(22)}$. The visual simplicity of the ROC data display and the quantitative expression of each curve make this technique a flexible and easily interpreted from data summary. Because an ROC curve displays data at continuously changing cut off points instead of one arbitrarily defined value, it is considered superior to data analysis. The area under the ROC curve provides information about the general goodness of the test, not the interpretation of test result ${ }^{(24)}$. A perfect test has an area 1.0 whereas a non informative test has an area 0.5 or less ${ }^{(25) .}$

A diagnostic test generally has a cut off value; each cut off point represents a sensitivity and specificity combination ${ }^{(26)}$. The sensitivity of test is its ability to identify patients with specific condition, whereas the specificity of a test is its ability to correctly identify patients without specific condition and the most useful diagnostic test has both high sensitivity and specificity. LII in the study was treated as a diagnostic test to identify patients with minimum, moderate and severe crowding then ROC curve was generated to contrast LII with three different categories of crowding. This allowed for selection of a cut-off point at a position along the curve that maximizes the objective of the test.

With respect to gender the results showed that there was no statistically significant difference for ALD and LII between males and females. The obtained result was in agreement with earlier studies ${ }^{(27-29)}$.

On the other hand some authors ${ }^{(30,31)}$ found that males having a significantly higher prevalence of malocclusion with incisor irregularity and orthodontic treatment needs than females. They concluded that the ethnicity, sex, age, combined to explain differences in irregularity index among the individuals.

The results also showed that no significant difference was found between upper and lower arches for ALD and LII. This result agreed with 
Bernabe and Flores ${ }^{(19)}$ and Ajayi ${ }^{(29)}$, but contradicts with a study by Mugonzibwa et al ${ }^{(32)}$ as showed that spacing was more often found in the maxilla, while crowding was more common in the mandible. Mugonzibwa et $\mathrm{al}^{(32)}$ study was conducted on Tanzanian African and Caucasian children, correspondingly, genetic factors may influence variation in space anomalies among different ethnic groups in addition to the environmental factors which can affect the occlusal similarities within families $^{(33)}$.

Regarding the association between LII and ALD in this study resulted in high correlation value $(-0.91)$, the negative sign in the calculated correlation coefficient indicated that the higher LII, the greater the negative ALD and vice versa. The high correlation offers theoretical support to consider the LII as an estimator of ALD, as previously applied in mixed dentition analysis and in permanent dentition ${ }^{(34)}$.

The result of this correlation is contradicted to that obtained by Harris $^{(18)}$. He reported a moderate and positive correlation (0.46), and considers that LII provides complementary information with ALD, which is more sensitive indicator of the amount of space actually needed for alignment as they are not measuring the same trait. This difference was attributed to the selection of the study samples. Harris used a study sample of post treatment relapse, and the only criterion for case selection was that the subjects come to the office for a long term post-retention recall appointment. So tooth size and /or arch perimeter (ALD analysis) could be affected by treatment.

Regarding the analysis of ROC curve for minimum crowding cases, LII of $>0 \mathrm{~mm}$ was the optimized cut-off point chosen to estimate minimum crowding with sensitivity 1.00 and specificity 1.00 . The results of ROC provided useful insights of the potentiality of LII to estimate negative ALD, particularly in estimating minimum crowding which was found to have the highest diagnostic capability. The most useful diagnostic test has both high sensitivity and specificity ${ }^{(35)}$. So based on high sensitivity and specificity of LII cut off point of $>0$, we might conclude that the more working time of ALD is not justified to identify patients with minimum crowding, and time could be saved if only LII is used in calculation the crowding. 
Egyptian

Orthodontic Journal

In the study of Bernabe and Flores ${ }^{(19)}$ when evaluated the ROC curve for minimum crowding a LII cut-off point of 2.45 was chosen with sensitivity 0.77 and specificity 0.72 . They stated that the highest sensitivity and specificity values was found for the cut-off point 4.00 $(0.78,0.76$ respectively), and LII have the highest diagnostic capability to estimate negative ALD more than $3 \mathrm{~mm}$ (moderate crowded arches) compared with 0 or $-6 \mathrm{~mm}$ of ALD in the dental arch. This conflict of the results could be related to the fact that their values could have been affected by low prevalence of ALD of the total sample and increasingly low prevalence of crowding in each of the dichotomized group. The prevalence of ALD greater than $0 \mathrm{~mm}$ was $55.5 \%$, whereas the prevalence of ALD greater than $6 \mathrm{~mm}$ was only $8.5 \%$. Meanwhile, in the present study the prevalence of the ALD were $21.4 \%, 21.8 \%, 22.7 \%$ for $0,3,6 \mathrm{~mm}$ ALD respectively, nearly there was an equal distribution of the ALD presented in all dichotomized group.

In moderate crowding cases, the ROC curve analysis suggested an optimized cut-off point of $>3.5 \mathrm{~mm}$ on LII to estimate negative ALD greater than 3 (moderate crowding), it presented with sensitivity 96.45 and specificity 97.96, while the LII cut-off point $>6 \mathrm{~mm}$ of sensitivity 91.95 and specificity 84.05 was chosen to estimate negative ALD greater than $6 \mathrm{~mm}$ ( severely crowded arches). This indicated that LII could be used in moderate and maximum crowding cases with excellent and good results respectively to estimate negative ALD.

By comparing the area under the ROC curve to gain information about the general goodness of the test, it was found that LII is a valid in estimating negative ALD in dental arch, and it could potentially be used especially in epidemiological settings as good and less time consuming measurement of crowding compared with visual inspection or computerized analysis ${ }^{(36,37)}$.

For case analysis when the axial inclinations of the anterior teeth diverge or when the teeth displaced but do not overlap, space analysis may consider essential to be incorporated into a total diagnostic scheme to be optimally useful to properly diagnose a malocclusion. 
Egyptian

Orthodontic Journal

\section{CONCLUSIONS}

On the basis of data obtained, the conclusion of the present study can be summarized as following:

1. There was high correlation found between LII and ALD.

2. LII was shown to have the highest diagnostic capability to estimate minimum crowding.

3. High sensitivity and specificity values for moderate and severe crowded arches offered a theoretical support to propose incisor irregularity as estimator for moderate and severe crowding.

4. The result may suggest that LII could be used in epidemiological survey as a valid measurement of ALD and for case analysis with minimum crowding.

\section{REFERENCES}

1. Gosney M B (1986). An investigation into some of the factors influencing the desire for orthodontic treatment. Br J Orthod. 13: 87-94.

2. Evans R and shaw W C. (1987). Preliminary evaluation of illustrated scale for rating dental attractivness. Europ. J orthod. 9: 314-318.

3. Shigenobu N, Hisano M, Shima S, Matsubara N ( 2007): Patterns of dental crowding in the lower arch and contributing factors. A statistical study. Angle Orthod. 77:303-310.

4. Lestrel P E, Takahashi O, Kanazawa E (2004). A quantitative approach for measuring crowding in the dental arch: Fourier descriptors. Am J Orthod Dentofacial Orthop, $125: 716-725$.

5. Grainger R M. (1967). Orthodontic Treatment Priority Index. National Center for Health Sevice,series II. No. 25, U S, Department of Health, Education and Wefare.Washington, D C 1967.

6. Summers C J (1971). The Occlusal Index: A System for Identifying and Scoring Occlusal Disoders. Am J Orthod, 59: 553-567.

7. Kinnar BK, Burker PH (1981) Quantitative assessement of the occlusal features. Br J Orthod. 8:149- 156. 
8. Brook P H, Shaw W C (1989). The development of an index of orthodontic treatment priority. Eur J Orthod, $11: 309-320$.

9. Daniels C. and Richamond S (2000). The Development of index of complexity, outcome and need (ICON). Br J Orthod, 27: 149 - 162.

10. Indian book, Orthodontic the art and science.pp110.

11. Shaw WC, Richmond S, O,Brien KD, Brook P Stephens CD (1991). Quality control in orthodontics: Indices of treatment needs and treatment standards. Br Dent J. 107-112.

12. World Health Organization (1997). Oral health surveys: basic methods. World Health Organization, Geneva.

13. Little R M. (1975). The irregularity index: a quantitative score of mandibular anterior alignment. Am J Orthod, $68: 554-563$.

14. Jenny $\mathrm{J}$ and Cons N C (1996). Comparing and contrasting two orthodontic indices, the index of orthodontic treatment need and the dental aesthetic index. Am J Orthod Dentofacial Orthop, 110: 410- 416.

15. Van der Linden F P. (1974). Theoretical and practical aspects of crowding in the human dentition. J A D A, 89: 139-153.

16. Van der Linden F P (1983). Development of the dentition. Chicago, Quintessense Publishers Co.

17. Battagel J M, Johal A S, Crow C P (1996 ). The assessment of crowding without the need to record arch perimeter. Part II: Crowded and irregular arches. Br J Orthod 23: 229-236.

18. Harris E F, Vaden J L, Williams R A (1987). Lower incisor space analysis: a contrast of methods. Am J Orthod Dentofacial Orthop, 92: $375-380$.

19. Bernabe E and Flores C (2006). Orthodontic treatment need in Peruvian young adults evaluated through dental esthetic index. Angle Orthod, 76: 417- 421.

20. Graber T M (2000). Current principles and technique. $3^{\text {rd }}$ ed. Mosby company, p.19. 
21. Bishara S E (2001). Textbook of orthodontics. Philadelphia, W B Saunders Co, pp.135-149.

22. Bland M (2000). An Introducion to Medical Statistics. $3^{\text {rd }}$ ed, Oxford University press, pp.276-278.

23. Han U K. and Kim Y H (1998). Determination of class II and class III skeletal pattern; receiver operating characteristic (ROC) analysis on various cephalometric measurement, 113: $538-545$.

24. Freudenthaler J, Celar A and Shneider B (2000). Overbite depth anteroposterior dysplasia indicator the relationship between occlusal and skeletal patterns using reciever operating curve analysis (ROC) analysis Eur J orthod, 22: 75-83.

25. McGorray S (2002). Senstivity, Specificity and related concepts. Semin Orthod, 8: $92-101$.

26. Wardlaw D, Richard J, David W (1992). Cephalometrics of anterior open bite; A reciever operating characteristic (ROC) analysis. Am J Orthod. Dentofacial Orthop, 101 : 234-43.

27. Tschill P, Bacon W, Sonko A (1997). Malocclusion in the deciduous dentition of Caucasian children. Eur J Orthod, 19 : 361-9.

28. Bassler-Zeltamann S, Kretschmer I, Goz G (1998). Malocclusion and the need for orthodontic treatment in 9-year-old children. Survey based on the Swedish National Board of Health and Welfare Scale. J Orofac Orthop, 59: 193-201.

29. Ajaya O E (2008).Prevalence of Malocclusion among School children in Benin City, Niggeria.Journal of Biomedical Sciences.

30. Buschang P H; Shulman J D (2003). Incisor crowding in untreated persons 15- 50 years of age: United States, 1988-1994. The Angle orthod. 73:502-508

31. Rahbar M E, Chaudhry N A, Haq A U (2010). Dental crowding and its relationship to arch dimensions. Gender Dimorphism. Pakistan Oral and Dental Journal 30:414-417

32. Mugonzibwa E, Eskeli R, Laine-Alava M (2008). Spacing and crowding among African and Caucasian children. Orthod Craniofac Res, 11: 82-89. 
33. Corrucini RS (1984). An epidemiologic transition in dental occlusion in world population, Am. J Orthod, 86: 419-425.

34. Moyers R E (1988) Handbook of orthodontics. Year book Medical Publishers, Chicago.

35. Bearn D, Wright J, Kay E (1996). Perception of orthodontic treatment need; Receiver operating characteristic analysis. Community Dent Oral Epidemiol, 24: 303 - 306.

36. Tran A M, Rugh J D, Chacon J A, Hatch J P (2003). Reliability and validity of a computer -based Little irrigylarity index. American Dental Association89: 139-153.

37. Kau CH, Littlefield J, Rainy N (2010). Evaluation of CBCT digital models and traditional models using Little irregularity index. Angle orthod. 80: 435-439 